\title{
Concorrência Desleal: Concepções do Processo de Mobilização Estratégica a partir de um Estudo de Caso
}

\author{
Rodrigo Holtermann Lagreca \\ Astor Hexsel
}

\section{ResUmo}

No contexto empresarial, mais do que no acadêmico, ganha destaque a discussão sobre as conseqüências dos negócios ilegais na arrecadação pública e no processo competitivo. A partir do entendimento de como esse fenômeno se organiza, este estudo investiga, com base em estudo de caso, as ações desenvolvidas pela Souza Cruz S.A, empresa dominante no setor brasileiro de cigarros para fazer frente à oferta ilegal ou informal, uma das formas de concorrência desleal. Constata-se que a organização desenvolve ações em dois níveis: no primeiro, são referidas as ações gerenciais para aprimorar o seu desempenho em face do problema e processo de aprendizagem dele derivado. No segundo nível, são descritas as ações diretas e indiretas sobre o governo, que é o agente legítimo para conter a informalidade. Essas ações incluem troca de informações com órgãos governamentais e atuação junto à opinião pública, como formas de buscar consentimento público e priorizar junto aos governos o cumprimento da lei.

Palavras-chave: indústria de cigarros; contrabando; contrafação; negócios ilegais.

\begin{abstract}
The discussion on the consequences of illegal business on the tax collection and on the competition process has arisen intensively in the business context, rather than in the academy. Once the understanding of how the phenomenon takes place is granted, this study investigates, based on a case study, the actions developed by Souza Cruz S.A., the Brazilian leading tobacco company to face the illegal market - one subject of unfair competition. The organization develops two-level actions: in the first level, the management actions, to improve the performance as for the problem and the consequent learning process. The second level actions are those exerted, both directly and indirectly, on the government, which is the legitimate part to struggle the informality. These actions include information exchange with government agencies and actions on the public opinion, as ways to gain public support and bolster the need for law enforcement.
\end{abstract}

Key words: tobacco industry; smuggling; counterfeiting; illegal business. 


\section{INTRODUÇÃO}

O entendimento da concorrência desleal ${ }^{(1)}$ parte da constatação de que nem toda a atividade econômica é formalizada. O setor informal da economia está presente, com força maior, nos países em desenvolvimento e nas nações outrora comunistas. Dada sua força, a maioria dos governos atingidos não estão em condições de competir com esse poder (Soto, 2001). Pelas facilidades e atrativos que oferece, segundo o citado autor, a informalidade acaba constituindo uma alternativa, quando os custos de obediência à lei pesam mais do que os benefícios. O mercado informal, no entanto, não é um fenômeno novo historicamente; está presente na economia mundial, sendo significante nas exportações e importações de diversos países (Johnson, 1974). Atualmente, as estimativas da Câmara Mundial de Comércio apontam que entre 5\% e 10\% do comércio mundial é praticado com produtos desleais, o que representa cerca de U\$ 300 bilhões/ano (Marshall, 2001).

A indústria de cigarros, à semelhança do que ocorre em outros setores - como os de artigos esportivos, música, software - vem sendo prejudicada pela atuação de ofertantes ilegais, seguidamente financiada pelo crime organizado (Cabral, 2001). O negócio ilegal de cigarros - contrabando, pirataria e evasão fiscal doméstica - constitui motivo de preocupação para a indústria e para o poder público, pela perda de mercado e pela evasão tributária decorrente da venda ilegal do produto, pois grande parte de seu preço final é representada por carga fiscal (Verdi, 2001). No Brasil, o mercado de cigarros é liderado por duas empresas multinacionais: a Souza Cruz e a Philip Morris. Na década de 90, a competição acentuou-se com a entrada de ofertantes de pequeno e médio porte no setor, significativa parcela de seu sucesso é atribuída a práticas de evasão fiscal. A Souza Cruz, com 76,2\% da participação entre os formais (Souza Cruz, 2003), posiciona-se como competidora dominante. Dada a sua participação, o perfil de oferta da empresa confunde-se com o perfil do próprio mercado, caracterizado pela baixa renda da maior parte dos consumidores, o que o torna vulnerável à oferta ilegal, que concorre justamente no segmento de baixo preço. No mercado total, considerando a soma da oferta formal e informal, a participação da Souza Cruz cai para $51,2 \%$ e a oferta informal domina $32,9 \%$, conforme estimativas feitas pelo Instituto Nielsen, nos meses de agosto e setembro de 2002 (Souza Cruz, 2003).

O mercado da oferta ilegal no país apresenta-se sob três formas: o contrabando - a mais representativa; a evasão fiscal em território nacional; a contrafação ou 
pirataria (Souza Cruz, 2003). Segundo Dieguez (2003), o suprimento desse mercado provém de duas fontes: ou é produzido por 12 empresas brasileiras de pequeno porte, a maioria delas envolvida em práticas de evasão fiscal, ou chega, principalmente do Paraguai, via contrabando. Cabral (2001) credita aos altos tributos e à sua diferença em relação aos países limítrofes, em especial o Paraguai, a viabilização da oferta ilegal de cigarros no mercado brasileiro. A primeira característica estimula a evasão fiscal e a segunda, o contrabando. Em geral, a oferta entendida como contrafação é disponibilizada de forma associada ao contrabando, perfazendo então dupla ilegalidade (Lagreca, 2003).

O tema ganha destaque adicional, pois a concorrência desleal toma espaço dos fabricantes formais num mercado que está em retração. Segundo Bueno (2003), medições do Instituto Nacional do Câncer - INCA - que consideram as vendas legais e ilegais, demonstram que o consumo médio de cigarros no Brasil em 2001 apresentou queda de $38 \%$ em relação ao consumo registrado 20 anos antes. Pesquisas do IBGE (Nicolini, 1999) também constataram queda nos gastos familiares mensais com fumo de 1,11\% em 1987 para 1,00\% em 1996.

Para as empresas que operam formalmente no setor, torna-se imperativo desenvolver estratégias para o enfrentamento dos concorrentes informais. $\mathrm{O}$ objetivo desse trabalho, então, é analisar como acontecem as ações defensivas desempenhadas pela Souza Cruz S.A., empresa dominante do setor de cigarros no Brasil, em face da concorrência desleal.

São discutidos, em primeiro lugar, os estudos e conceitos que servem de base analítica ao caso investigado. Logo, apresentam-se o caso e sua análise. A seguir, são apresentadas as conclusões sobre as estratégias para o enfrentamento da concorrência desleal no setor em estudo. Espera-se que o trabalho contribua para a reflexão e para as práticas organizacionais, nas situações concorrenciais em que a informalidade seja fator relevante.

\section{Referencial Teórico}

O entendimento da dinâmica das relações entre a concorrência desleal e seus impactos na competitividade organizacional e governos passa pela análise de competitividade e padrões de concorrência proposta por Ferraz, Kupfer e Haguenauer (1996); pelo conceito de estratégia emergente de Mintzberg (2000); pelo modelo de análise das indústrias de Porter (1986). Precedendo essa análise, são discutidas as dinâmicas da informalidade a partir de pesquisas realizadas em países de alta renda. 


\section{Relações entre Práticas Ilegais, Atividades Econômicas Regulares e Governos}

Os estudos que melhor situam os efeitos da concorrência desleal sobre os negócios regulares, neste particular especificamente sobre a indústria de cigarros, foram desenvolvidos por Merriman, Yurekli e Chaloupka (2000), Joossens, Merriman, Yurekli e Chaloupka (2000) e Thursby, Jensen e Thursby (1991) e Thursby e Thursby (2000). A produção desses dois grupos de autores relaciona, respectivamente, os impactos econômicos múltiplos acarretados pelas práticas ilegais no setor de cigarros e as estruturas concorrenciais influenciadas pelas atividades de contrabando.

Apesar de as considerações teóricas sobre concorrência desleal terem sido desenvolvidas em países de alta renda, elas são aplicáveis a um amplo leque de Estados que participam da sociedade mundial (Merriman et al., 2000). Observa-se que, dentre as práticas desleais no setor de cigarros, as de contrabando são as mais representativas. Para seu entendimento, destaca-se o conceito de Deflem e Henry-Turner (2001), que define contrabando como a importação clandestina de bens de uma jurisdição para outra. Considerase, por extensão, que o mercado ilegal inclua também a prática de evasão fiscal dentro de uma mesma jurisdição (Deflem \& Henry-Turner, 2001; Merriman et al., 2000).

Os efeitos do aumento dos preços do cigarro para consumo têm sido extensivamente estudados e evidenciam que tal alta nos custos finais do produto faz com que haja incremento nas arrecadações públicas, bem como reduções em seu consumo (Jonhson, 1974; Joossens et al., 2000; Thursby et al., 1991; Thursby $\&$ Thursby, 2000). Porém, como os próprios autores sugerem, ao mesmo tempo que a arrecadação aumenta, abre-se espaço para que o contrabando também cresça, porque, como o preço do cigarro freqüentemente está atrelado a altas cargas tributárias, isso confere apelo adicional para os potenciais contrabandistas (Merriman et al., 2000). Há concordância entre os autores que também as disparidades de preço entre jurisdições são grandes incentivadoras do contrabando (Deflem \& Henry-Turner, 2001).

Os países 'sub' ou 'em' desenvolvimento são notoriamente mais sensíveis ao contrabando do que os países desenvolvidos, uma vez que dispõem de menos recursos para combater a ilegalidade, o que faz aumentar o fluxo do comércio ilegal e, em decorrência, o custo de tarifas e taxas (Joossens et al., 2000; Merriman et al., 2000).

Segundo Naya e Morgan (1974), apesar da baixa quantidade e da pouca 
credibilidade dos dados econômicos à disposição sobre os países menos desenvolvidos, seu exame é necessário para a formulação de planos de desenvolvimento, relacionados também às medições e desdobramentos do comércio ilegal. Em corroboração mútua de pensamento, Merriman et al. (2000) e Joossens et al. (2000) apontam as dificuldades de se estudar o contrabando com a metodologia econométrica convencional, visto que, por ter natureza ilegal como variável dependente, ele é muito mais inferido do que diretamente contabilizado, em qualquer país do mundo. Dessa forma, o nível de contrabando é medido pela diferença entre a demanda total prevista - econometricamente medida - e o recolhimento de impostos de fato ocorrido. Soma-se a isso, como destacam Merriman et al. (2000), a tendência de os países pobres terem maior corrupção, confirmada pelos índices menores de contrabando em países vistos como menos corruptos. Na abrangência transnacional, as dificuldades maiores desses países em controlar os fluxos de capitais também podem facilitar o comércio ilegal (Bhagwati, Krueger, \& Wibulswasdi, 1974).

A fim de conter a prática ilegal, a fiscalização do cumprimento de leis anticontrabando freqüentemente é defendida como o aspecto mais importante no seu controle (Nadelmann, 1993, como citado em Deflem \& Henry-Turner, 2001). Segundo Deflem e Henry-Turner (2001), a importância do cumprimento das leis anticontrabando (law enforcement) está no interesse das nações em proteger sua base de receitas tributárias. Isso tem levado as atividades de law enforcement a focar a recuperação de perdas tributárias em detrimento da efetiva punição ao contrabandista.

Existe uma relação inversa entre a participação do contrabando e o conseqüente preço relativo do mercado e a fiscalização dentro de uma jurisdição (Joossens et al., 2000; Merriman et al., 2000). O efeito da fiscalização reduz o contrabando, aumenta o preço e reduz o consumo adicional causado pelo contrabando (Thursby, Jensen, \& Thursby, 1991). Igualmente, faz com que as receitas dos contrabandistas caiam e seus custos aumentem, pelo fato de necessitarem desenvolver meios para escapar à fiscalização. Esses meios incluem camuflar vendas ilegais entre as vendas legais para evadir os impostos e confundir as autoridades (Thursby et al., 1991; Thursby \& Thursby, 2000).

Os governos, ao aumentarem os impostos visando conter o consumo, levam os contrabandistas a retaliar. Isso se traduz no aumento do percentual de contrabando nas operações das firmas que atuam de forma mista (legal e ilegal), caracterizando a camuflagem. A camuflagem está relacionada à disparidade de preços praticados no mercado e também ao grau de competitividade de uma indústria, ambas condições necessárias para que a concorrência desleal tenha espaço (Thursby et 
al., 1991; J. G. Thursby \& M. C. Thursby, 2000). A partir das análises realizadas, Thursby et al. (1991) apontam o fato de que nem todas as empresas de um setor operam com o contrabando, camuflado ou não. A opção de contrabandear ou não é estabelecida por dois fatores: primeiro, há diferenças de custos entre as empresas com o contrabando; segundo, porque algumas empresas têm tal poder de mercado que não necessitam praticá-lo. Assim, há coexistência de empresas que atuam legalmente com as que operam de forma mista (legal e ilegal).

Os autores sinalizam que a camuflagem acontece com maior incidência em mercados em que prevalece a concorrência imperfeita, como historicamente acontece com a indústria de cigarros. A camuflagem do contrabando faz com que o poder de mercado seja deslocado da indústria para a estrutura de distribuição. Um elemento que dificulta a identificação e o combate ao contrabando, segundo Bhagwati e Hansen (1974) e Thursby et al. (1991), é que os consumidores podem não saber que estão consumindo produtos contrabandeados e camuflados em substituição aos produtos legais, visto que as fontes de suprimento e manufatura podem ser as mesmas ou similares.

\section{Relações entre o Macroambiente e a Estratégia das Organizações}

Ao analisar a questão da competitividade, Ferraz et al. (1996) indicam que são três os grupos de fatores que determinam a competitividade das empresas: fatores empresariais, que estão relacionados à capacitação, competências e à estratégia da organização; fatores estruturais e fatores sistêmicos, que estão relacionados ao padrão de concorrência vigente em determinado mercado. Os fatores estruturais são aqueles sobre os quais a empresa tem capacidade parcial de intervenção, limitada pelo processo de concorrência. Apresentam especificidades setoriais mais nítidas do que os fatores empresariais, na medida em que sua importância está relacionada à indústria em que atua e a seu padrão de concorrência peculiar. Conceitualmente, os fatores estruturais estão muito próximos do modelo de análise das indústrias de Porter (1986), que relaciona os fatores de sucesso das organizações diretamente às condições da indústria em que a empresa se insere. Esses fatores são ditados pela presença de cinco forças competitivas, que interagem com diferentes intensidades. Em extensão, o autor afirma que empresas com participação setorial dominante têm condições de interferir na estrutura da indústria, como é o caso em estudo.

Os 'fatores sistêmicos', também denominados macroambientais, compreendem os aspectos inerentes às contingências políticas, econômicas, institucionais e geográficas. Por estar no escopo mais amplo de influência sobre 
a estrutura concorrencial, privilegia-se esse grupo de fatores que, de forma sintética, segundo Ferraz et al. (1996), são: os 'macroeconômicos', como a taxa de câmbio, a carga tributária e as políticas de crédito e juros; os 'políticoinstitucionas', que compreendem a política tributária e o apoio fiscal ao risco tecnológico; os 'regulatório-legais' que dizem respeito à proteção da propriedade intelectual e industrial, à preservação ambiental e à defesa da concorrência; os 'infra-estruturais que englobam' a disponibilidade energética, transportes e telecomunicações; 'os sociais que resultam' dos sistemas de qualificação de mão-de-obra, política trabalhista e seguridade social; os 'internacionais' que se associam às tendências de comércio mundial, aos fluxos de capital e às relações e acordos internacionais.

Para alinhar os fatores sistêmicos de competitividade ao desempenho organizacional, busca-se entender o papel da estratégia neste contexto. Pelo conceito das 'estratégias emergentes' (Mintzberg \& Quinn, 2001), entendidas como estratégias não-planejadas, depura-se que a empresa tem a possibilidade de aprender ao longo do tempo com uma situação - ou contexto - e organizar-se a partir disso sobre como melhor lidar com ela. Mariotto (2003) sugere que esse entendimento de estratégia é o melhor caminho para regrar o funcionamento das empresas, uma vez que as mudanças na sociedade mundial e o acirramento na competição não permitem a elaboração de planos complexos, exigindo mais flexibilização na resposta organizacional. Corroborando o pensamento, Ferraz et al. (1996) afirmam que a estratégia tem o papel de adequar o comportamento da empresa, com suas limitações de recursos e capacitações, aos padrões de concorrência, estabelecidos pelo ambiente político e econômico.

Em extensão, uma opção de ações empresariais, segundo Porter (2002), erroneamente confundida com estratégia, é a busca da eficácia operacional, que tem como objetivo desempenhar atividades similares aos rivais de forma otimizada, capacitação para utilizar melhor os ativos da empresa. Ela é imprescindível para a obtenção do desempenho superior, mas não é o bastante para assegurar uma condição competitiva sustentável ao longo do tempo, pois rapidamente essas melhores práticas são imitadas. Como aspecto negativo, o autor destaca que a eficácia operacional leva as empresas a competir por preços baixos.

A interação das dimensões comentadas na seção do referencial teórico constitui o esquema de análise deste trabalho, cuja proposição é visualizar como essas diferentes referências interagem e impactam as atividades econômicas regulares - empresa e indústria - conforme representado na Figura 1.

Esse esquema de análise aponta que desequilíbrios na estrutura sistêmica do macro-ambiente permitem que o fenômeno da concorrência desleal logre seu espaço, passando esta a também fazer parte do ambiente, representado, na 
Figura 1, pela zona de sobreposição das duas elipses. Como consequiência, tem-se que a nova força ambiental afeta a indústria formal estabelecida, alterando sua estrutura regular. Isso conduz a indústria a desenvolver ações para novamente alterar a estrutura macroambiental, através de um processo estratégico emergente, representado, na Figura 1, pela seta pontilhada. Seus desdobramentos estão descritos nas seções seguintes.

Figura 1: Interações de Ambiente, Indústria e Oferta Ilegal

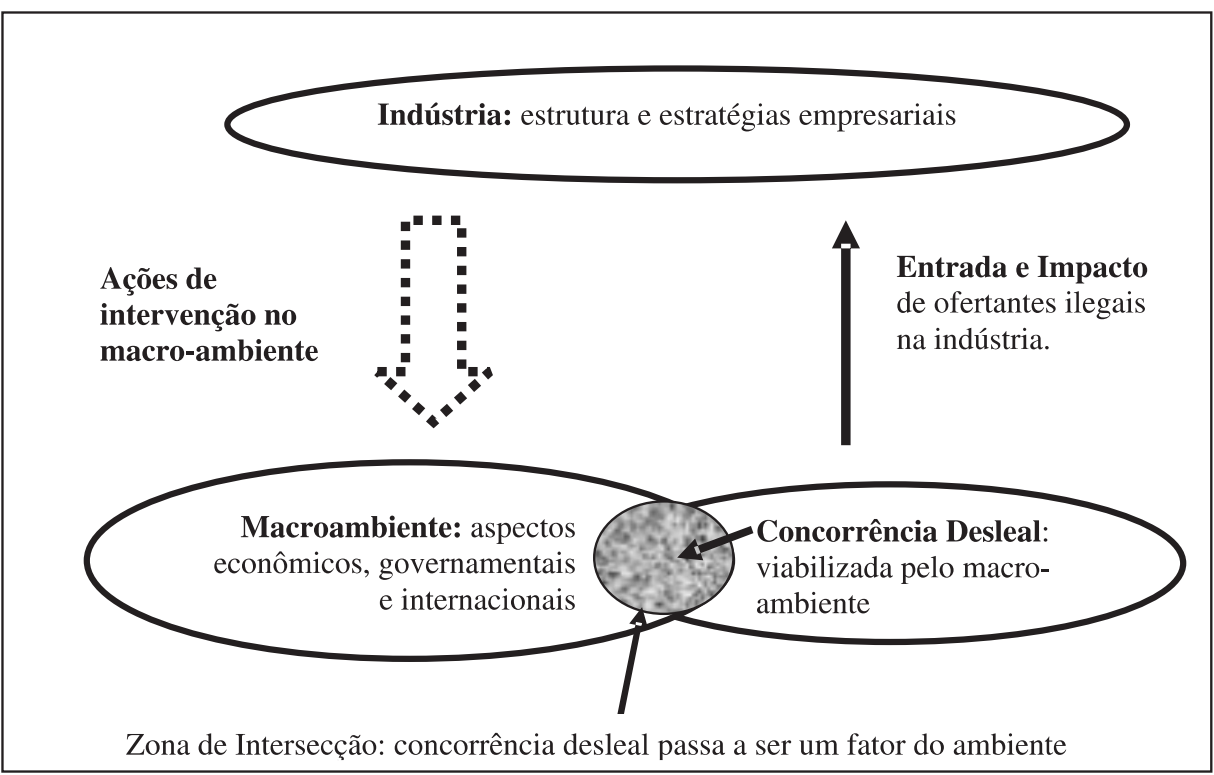

Fonte: Elaborado pelos autores.

\section{MÉTODO}

Para desenvolvimento deste artigo, optou-se pelo método de estudo de caso. A escolha desse método ajusta-se às proposições de Yin (2001), Bruyne, Herman e Schoretheete (1991) e Porter (1991), que o consideram adequado a uma situação de pesquisa em que estão presentes as seguintes características: o fenômeno observado acontece em tempo presente; os limites entre o fenômeno e o contexto não estão claramente definidos; o entendimento das ações estratégicas pressupõe a consideração de grande número de variáveis ambientais inter-relacionadas; o propósito do estudo é pesquisar com profundidade uma grande quantidade de informações, sem preocupação com a representatividade estatística dos resultados. 
A pesquisa desenvolveu-se em duas etapas. Na primeira, com o objetivo de melhor situar o problema, buscou-se entender, a partir de levantamento de dados secundários, as principais características da oferta informal relacionada à indústria de cigarros. Nesta etapa, foram coletados dados em relatórios, anais de congressos, publicações da mídia convencional e publicações técnicas no exterior.

$\mathrm{Na}$ segunda etapa, com base em entrevistas realizadas com executivos da organização, objetivou-se compreender as estratégias desenvolvidas para fazer frente à oferta ilegal. Para as entrevistas, tendo como base o referencial teórico, foi utilizado um roteiro semi-estruturado em que se agruparam as questões em três grandes tópicos: ações de eficácia operacional; ações de intervenção no macroambiente; e o processo de formulação estratégica. Procurou-se avaliar a natureza emergente ou não da estratégia e a questão do aprendizado organizacional. Foram feitas entrevistas com 14 executivos da empresa, das áreas funcionais mais afetadas pela atuação da concorrência desleal, no período compreendido entre novembro de 2002 e agosto de 2003. Por sua solicitação, seus depoimentos foram mantidos anônimos. Para a plena compreensão do contexto, foram também colhidos depoimentos de varejistas, fiscais públicos e representantes de ONGs, além de observação direta em operações de venda e suprimento de produtos informais.

As entrevistas foram transcritas e analisadas em seu conteúdo. As narrativas foram organizadas inicialmente em três categorias temáticas: ações quanto à eficácia operacional, ações que buscam influir no ambiente; características do processo estratégico. Na análise final, optou-se por discutir essa última categoria dentro do contexto das duas primeiras. Nas entrevistas, os respondentes foram estimulados a contemplar a dimensão temporal das respostas, o que permitiu enriquecer a análise final com avaliações sobre perspectivas, propostas e sugestões para o desenvolvimento de ações em parcerias com outras organizações, públicas e privadas. Por fim, com o propósito de aumentar a compreensão das narrativas e aumentar a sua fidedignidade, foi feita triangulação de dados entre as informações resultantes dos dados primários e secundários.

\section{O Mercado Ilegal Brasileiro de Cigarros: Características FuncionaIS}

A atuação da oferta ilegal, cuja prática em escala industrial afeta a concorrência regular, é transposta em vários aspectos à realidade do mercado brasileiro.

Cientes das especificidades do mercado, os ofertantes ilegais desenvolvem um processo dinâmico, variando rapidamente as fontes de suprimento oriundas de 
diferentes lugares (incluindo países), o que lhes permite, conseqüentemente, lograr no ludibrio da fiscalização e evadir impostos, seja na produção, seja na distribuição de cigarros (Lagreca, 2003). O histórico da oferta ilegal no Brasil remonta à década de 90, quando as exportações das empresas dominantes do setor para países do Mercosul que, por incentivos fiscais à exportação, eram isentas de imposto, retornavam ao país com preço final abaixo do tabelado pelo governo para o mercado doméstico, caracterizando contrabando (Nicolini, 1999). Produziase assim uma situação, em que a mesma marca de cigarro era vendida pela operação de contrabando com preço mais acessível do que pela operação de venda no mercado interno.

Naquele momento, segundo a mesma fonte, a indústria sofreu acusações de alimentar essa dinâmica, por não controlar suas vendas a distribuidores que praticavam o contrabando. A partir de 1999, com a taxação de $150 \%$ aplicada pelo governo brasileiro à exportação de cigarros a esses países, houve mudança na estrutura da oferta ilegal, com a montagem de grande número de plantas industriais em território paraguaio, a fim de abastecer ilegalmente o mercado brasileiro (Lagreca, 2003). Essas unidades supriam-se do fumo fabricado no Brasil, pois sua exportação se manteve isenta de imposto. Posteriormente, em 2001, a taxação foi estendida também à exportação de insumos de produção de cigarros (fumo, papel etc.), o que jogou na ilegalidade também o suprimento de matériasprimas originadas do Brasil às fábricas situadas nos países limítrofes (Verdi, 2001). Com essa medida, fontes da indústria destacam que, para obter as matériasprimas necessárias à manufatura, os ofertantes instalados no Paraguai passaram a triangular operações de importação de fumo brasileiro. O fumo passa a ser exportado a países da África e, a seguir, reexportado para o Paraguai. Muitas vezes, em operações fraudulentas, as partidas são remetidas diretamente ao Paraguai, sem embarque físico aos países africanos.

A ilegalidade incrementou-se também dentro do Brasil, pois os ofertantes de menor porte passaram a intensificar sua produção camuflada - remessas ilegais entre remessas legais - de forma a dispor de opções de suprimento, já que os proprietários das empresas situadas no interior do Brasil ou no exterior, em muitos casos, eram os mesmos (Cabral, 2001). Um fator que pode fomentar essa competência reside na presença de ex-executivos das multinacionais do setor e de ex-funcionários da Receita Federal, assessorando e até mesmo gerenciando não só as atividades das empresas instaladas no Paraguai, como das empresas de menor porte, localizadas Brasil (Evelin, 1998).

Contrariamente ao que acontece no mercado ambulante - os conhecidos camelôs - que trabalha unicamente com produtos ilegais, a concorrência desleal opera com força muito maior nos varejos estabelecidos. As medições a esse respeito 
apontam que praticamente a metade de toda a base varejista no Brasil comercializa pelo menos uma marca ilegal, mostrando grande capacidade logística (Cabral, 2001). A presença da concorrência desleal nesses varejos, entendida como contrabando, evasão fiscal e contrafação, está apresentada no Quadro 1, onde se lê a participação geral de sua oferta.

\section{Quadro 1: Distribuição da Oferta Informal de Cigarros no Mercado Brasileiro em 2002}

\begin{tabular}{|c|c|}
\hline Contrabando & $58 \%$ \\
\hline Evasão Fiscal & $29 \%$ \\
\hline Contrafação & $13 \%$ \\
\hline
\end{tabular}

Fonte: Nielsen (2002) como citado em Souza Cruz (2003).

Vê-se que a oferta representada pelo contrabando é a mais significativa, seguida pela oferta representada pela evasão fiscal, produtos fabricados no Brasil sem o recolhimento de impostos. O volume entendido como contrafação ou pirataria, correspondente a marcas conhecidas produzidas de forma ilícita sem autorização do fabricante e sem recolhimento fiscal - é a menor parte do total. Em congruência, Marshall (2001) afirma que, geralmente, quem pratica esses crimes os pratica conjuntamente. Para o autor, contrabando e falsificação são praticamente sinônimos, pois os números de apreensões de produtos falsificados, no primeiro semestre de 2001, nas diversas alfândegas do mundo chegaram a 560 milhões de unidades de cigarros. Todas essas cargas estavam sendo comercializadas ilegalmente, caracterizando-se também como contrabando. Ao exemplificar as práticas brasileiras, Cabral (2001) afirma que a oferta de produtos falsificados no Brasil, em grande parte, chega ao país proveniente de países limítrofes, podendo, assim, ser enquadrada simultaneamente como contrafação e contrabando.

\section{O Processo Estratégico: a Resposta da Organização}

As ações empreendidas pela Souza Cruz são entendidas como processo estratégico emergente, cujo escopo é centrado em processos de aprendizagem. Tais ações estruturam-se em duas direções: ações de busca por desenvolvimento de competências e eficácia operacional - relacionadas à tomada de decisão e otimização de desempenho; ações de relacionamento e intervenção no ambiente. A primeira visa a melhor posicionar a empresa em face da oferta ilegal; a segunda pretende obter isomorfia com seu ambiente (foco no governo), objetivando aprimorar ações de fiscalização. 


\section{Otimização de Competências e Busca pela Eficácia Operacional}

As estratégias organizacionais adotadas para enfrentar a oferta ilegal partem do uso da estrutura operacional já montada e do aprimoramento de suas competências e capacitações. A seguir, descrevem-se as ações implementadas por área de atividade funcional.

a) Marketing. Com o banimento da publicidade de tabaco no Brasil, em janeiro de 2001, as formas das empresas do setor comunicarem aos seus consumidores ficou basicamente restrita aos canais de comercialização (varejos). Para os pontos de venda, ou varejos, são desenvolvidos materiais de merchandising mais apropriados para competir com o produto informal. Neste caso, trata-se de materiais que mantenham a identidade de seus produtos e da empresa, confeccionados com custos mais baixos. São desenhados materiais com apelo popular, enfatizando o preço dos produtos, destinados às áreas nas quais a concorrência desleal é mais forte - áreas mais pobres dos grandes centros urbanos ou áreas economicamente defasadas. Segundo a empresa, é importante que o consumidor de baixa renda perceba que o produto está disponível como alternativa de preço acessível.

b) Atendimento ao consumidor. $\mathrm{O}$ investimento no canal de atendimento ao consumidor é percebido pela Souza Cruz como extremamente valioso, uma vez que por ele a empresa obtém a oportunidade de manifestar sua posição diretamente ao público. A Souza Cruz buscou aprimorar a relação com o consumidor via central de atendimento telefônico, atividade que envolve o treinamento e desenvolvimento dos recursos humanos implicados nessa operação. São desenvolvidos scripts, em que constam informações sobre os diversos danos trazidos pelos produtos da indústria informal: legal, econômico, para a saúde pública etc. Esta estrutura ganha importância em uma empresa tabagista, uma vez que, com a restrição da propaganda de cigarros no Brasil, se tornou necessário o máximo aproveitamento dos canais de comunicação disponíveis. Estratégia semelhante é aplicada no website da empresa, levando a uma intersecção entre este tópico e o anterior.

c) Recursos humanos. Elaboração, pela área de recursos humanos, de uma sistemática de avaliação dos executivos da empresa, contemplando a existência do mercado ilegal. A Souza Cruz avalia periodicamente o desempenho de sua equipe, empregando diversos parâmetros de medição de desempenho, bem como o exame de sua contribuição ao combate da ilegalidade. Todos os executivos são avaliados por sua participação no combate à indústria informal, em seu espectro de gestão. A prática consiste em incluir, na pontuação de avaliação anual do executivo, as medidas por ele tomadas 
contra a ilegalidade, sendo esse um dos indicadores mais valorizados. A avaliação define o percentual da participação do funcionário nos resultados (lucros) que cada executivo recebe (bônus anual), estando também relacionada às perspectivas de plano de carreira.

d) Vendas e distribuição (Trade Marketing). Adota-se a implementação de mini-distribuidores (MD) como principal ferramenta nessa área de atividade da empresa. Esses agentes de venda foram concebidos especificamente para reduzir os custos de distribuição e são considerados como ferramenta das mais representativas para restringir a disponibilidade da concorrência desleal. É facultado aos MD, como agentes terceirizados, a opção de comercializarem outros produtos que não cigarro, reforçando seu orçamento operacional. Seu propósito é atuar nas áreas em que os distribuidores de cigarros informais concentram seu foco: nas regiões periféricas dos grandes centros e áreas populacionais menos densas.

e) Eventos. Realização de eventos e atividades que informem e mobilizem o varejista quanto à relevância de barrar a oferta ilegal. Um dos exemplos dessa iniciativa foi o Fórum de Responsabilidade Social do Varejo, com algumas edições realizadas em conjunto pela Souza Cruz e Philip Morris. O evento aborda, entre outros aspectos, a informalidade no setor. Ele é até agora a única ação conjunta levada a cabo pelas multinacionais para ao público varejista.

f) Pesquisa e desenvolvimento $(\boldsymbol{P} \& \boldsymbol{D})$. Fomento, na área de $P \& D$, de inovações que objetivem a constante diferenciação do produto. Isso envolve projetos gráficos para distinção das embalagens e dos componentes do próprio cigarro, com uso de impressões e grafias diferenciadas nos traços e nos materiais empregados. No entanto essas ações têm efeito efêmero - alguns meses - pois as quadrilhas especializadas em falsificação rapidamente as copiam e recolocam os produtos formais em situação de vulnerabilidade.

g) Industrial e logística. Inclui incremento no controle das operações internas e externas que envolvem fornecedores, operações terceirizadas e remessas de matérias primas próprias e de outros competidores, objetivando dificultar o abastecimento à concorrência desleal. Segundo relatos, há dificuldade em obterse êxito, mesmo com a alta verticalização da cadeia, dada a agilidade dos ilegais em variar as fontes de suprimento do fumo, já que algumas empresas operam tanto no Brasil quanto no Paraguai. Isso forma uma rede de abastecimento que facilita a transferência do fumo produzido no Brasil para o Paraguai, sem o recolhimento da taxa de $150 \%$. 


\section{Ações de Relacionamento com o Ambiente}

Para combater o problema do mercado ilegal, a empresa estabelece relacionamentos com organismos governamentais e não governamentais. As razões da mobilização estratégica da organização contra a concorrência desleal pode ser entendida pelo depoimento a seguir.

"A oferta informal hoje no Brasil representa 32,9\% do mercado, mas em algumas áreas, como os estados da região Norte e Nordeste, chega a 70\%. O assunto é considerado estratégico para a empresa, porque hoje é 32,9\%, amanhã pode ser $50 \mathrm{ou}$ 60\%, aí acaba nosso negócio."

\section{Ações Junto à Mídia para Convencimento da Opinião Pública}

O convencimento da opinião pública é visto pela empresa como de importância fundamental para que todas as demais ações de combate possam acontecer. O meio para chegar ao êxito nessa iniciativa é a publicização, isto é, a utilização da imprensa, de eventos e congressos, que contam com apoio de outras indústrias afetadas pelo mercado ilegal, para a divulgação de informações. Sobre as relações entre governos e opinião pública, um executivo explica que "a empresa usa todas as oportunidades disponíveis para abordar esse assunto na mídia", o que conduz a discussões e compromissos de ação por parte dos governos.

Aspectos que envolvem a mídia também merecem destaque adicional, especialmente por ser a organização pertencente à indústria tabagista. Isso é acentuado pelas acusações que a indústria sofreu nos anos 90 por haver-se envolvido em fluxos de contrabando com países vizinhos, principalmente o Paraguai (Nicolini, 1999). Essa percepção, de acordo com os relatos captados, tem-se modificado. As estatísticas da empresa apontam que o teor das matérias publicadas pelos jornais têm sofrido alteração, não mais relacionando a indústria de cigarros - os grandes competidores - às práticas desleais de mercado. Os planos da empresa nessa área incluem manter a estratégia que vem sendo adotada junto à imprensa.

\section{Ações Junto aos Organismos Públicos para Execução da Fiscalização}

A empresa entende que quem deve fazer o combate propriamente dito ao mercado ilegal é a ação governamental de fiscalização. A empresa julga que seu papel é contribuir com informações aos órgãos do governo, com dados dos impactos na cadeia de suprimento, na evasão fiscal e até na atividade criminal. Nesse sentido, 'fazemos contatos com as autoridades para expor o problema e acompanhar o desenvolvimento das ações'. 
A fim de facilitar as atividades de fiscalização, a empresa troca informações com as polícias e os órgãos públicos. Existe também mobilização por parte das empresas com vistas à divulgação desse problema, via associações e ONGs. Na opinião de um executivo, 'isso já está acontecendo, mas deveria ser mais forte, deveria haver mais interação entre as empresas e principalmente entre os organismos governamentais'. Sobre as relações específicas entre as empresas privadas, é relatado que 'há diferenças entre os níveis de informação e pesquisa, que ainda não são compartilhados', mesmo entre empresas de distintos setores que sofrem com a concorrência desleal.

\section{Aspectos Ambientais Inseridos no Combate à Concorrência Desleal}

O problema da concorrência desleal na organização pesquisada gera um processo de mobilização, com diferenças de percepção entre seus gestores. Quando os líderes do processo foram questionados sobre a forma de gerir uma empresa que conta com uma concorrência desleal de tal magnitude, observou-se consonância de intenções, porém com algumas diferenças quanto às formas de atingir as metas.

Uma opinião prioriza a exatidão sobre como são as dinâmicas desse mercado, o que leva a focar suas decisões, considerando suas características. Isso faz com que haja 'maior grau de controle sobre as informações internas, incluindo fornecedores, estratégias e as pessoas que as detém, uma vez que quase todas as decisões são tomadas pautadas na existência desse mercado [o ilegal]'. Outra opinião sublinha o aspecto de aprendizagem e aperfeiçoamento organizacional, posiciona que 'a primeira coisa é a empresa acreditar internamente que pode destruir isso', destaca que o combate à ilegalidade não é processo rápido; 'é necessário levar isso em consideração para seu negócio como um todo, deve ser uma das três prioridades principais, e a direção da companhia tem isso bastante claro'. Na área de marketing, um executivo sugere que uma das saídas que ele vê para gerir o negócio é a adequação do tamanho da empresa ao mercado de marcas de alto preço, mantendo-a menor em tamanho, porém mais rentável; vender menos, mas com menores custos operacionais. Ele crê ser esta uma decisão já deliberada pela empresa, ainda que não oficializada. Sua suspeita é esta; 'até quando a empresa vai conseguir manter suas marcas de baixo preço competindo com as marcas ilegais?'

As dificuldades de mercado em face da concorrência desleal crescem, quando a empresa tem de lidar com o mercado ilegal dentro de seus domínios - entendido como a penetração dos varejos formais com produtos ilegais: 'a Souza Cruz acaba sendo vista como alguém que quer prejudicar o negócio 
dele. A presença dos informais nos varejos é um problema adicional para a empresa, porque também são nossos clientes'. Conforme já apresentado, o combate à concorrência desleal envolve operações em mais de um país, demandando amplos esforços de fiscalização. Os relatos indicam a possível falta de vontade política e institucional do Paraguai e do Uruguai em coibir a indústria ilegal lá instalada, uma vez que essa estrutura desempenha papel econômico e social. Isso dificulta a implementação de ações coordenadas entre as polícias dos países envolvidos, condição necessária para que a oferta ilegal retroceda. Como o cigarro é produto controverso e também supérfluo, ele torna-se alvo fácil de medidas de elevação tributária, uma vez que: 'você não vai encontrar muitas resistências a essa taxação e é onde hoje existe uma tendência mundial'. Desta forma, os executivos temem perder mercado progressivamente, quando ocorrerem decisões de aumento de impostos, uma vez que isso naturalmente não afeta a oferta ilegal.

As opiniões dos executivos convergem também para a necessidade de a empresa aprender a lidar com o mercado informal, admitindo que o preparo para enfrentá-lo é um processo que está sendo construído: '[...] o problema é muito novo, e não há nada desenhado, escrito, teorizado, mostrando como lidar com isso. As empresas têm muita dificuldade em lidar com a informalidade. Não há literatura em estratégias ou ações, no setor público nem no privado para lidar com isso. O aprendizado é feito por tentativa e erro, ou o que funciona é melhor; o que não funciona não é melhor; acertos e erros, testando. As empresas não estão estruturadas, e o governo não está estruturado, não têm isso claro em seus programas. [...] acho que temos entre 30 e $40 \%$ do caminho andado. Já sabemos o que fazer, como tratar o problema, mas temos que viabilizar COMO fazer. Dependemos muito do governo e do judiciário, não conseguimos ainda vislumbrar alternativas suficientemente eficientes para combater a ilegalidade em curto prazo. Há corrupção, as leis são brandas, não coíbem esse crime: as penas são leves e as multas são irrisórias. Também não sabemos se as ações que queremos implementar vão reduzir o mercado informal.'

Na Figura 2, sintetizam-se essas ações, envolvendo seus diversos elementos. 


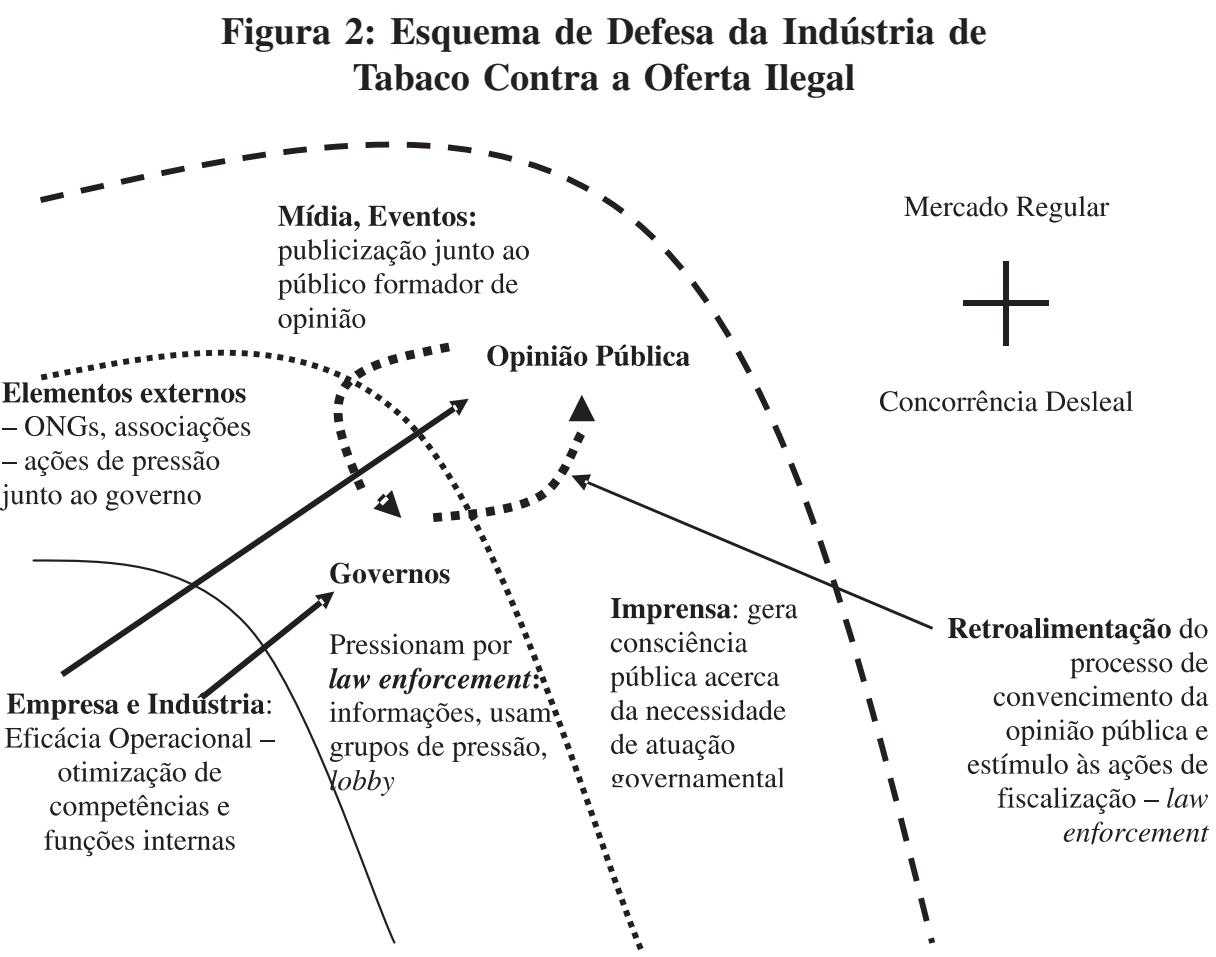

Fonte: elaborado pelos autores.

A análise dos depoimentos leva a considerar que as ações promovidas pela empresa para defender-se da concorrência desleal dependem de sua capacidade de interferência no ambiente. Observam-se três esferas de atuação: empresa e indústria; governos; opinião pública. No primeiro nível empresa e indústria - estão listados os esforços gerenciais de aperfeiçoamento do negócio, entendidos como eficácia operacional. No segundo nível, é apresentado o grupo de ações empenhado junto ao poder público, o que inclui trâmite de informações sigilosas (obtidas via atuação de esforços privados), lobby e apoio de entidades de classe ligadas ou mantidas pela indústria, que se somam aos esforços diretamente realizados pela organização e sua indústria. No terceiro nível, está a opinião pública, em que os principais agentes de formação de opinião são a imprensa, os stakeholders e a classe econômica como um todo. Nesta esfera, são envidados esforços que possibilitem criar awareness (consciência) acerca do problema da oferta ilegal e assim obter respaldo público para que o governo priorize a contenção da ilegalidade, via fiscalização, fechando o ciclo de retroalimentação das ações desenvolvidas pela empresa e suas resultantes. 


\section{Conclusóes}

A partir do caso estudado, evidenciam-se diversas áreas de intersecção entre o caso brasileiro de mercado ilegal de cigarros e as práticas em outros países, comprovando que exemplos de atividades desleais seguem alguns padrões específicos. Dentre estas, destaca-se a apropriação pelos contrabandistas das fragilidades da fiscalização, seja pela corrupção ou pela insuficiência de recursos por parte dos agentes públicos. Reitera-se também a atratividade da mercadoria cigarro ao contrabando - por seu volume físico reduzido aliado ao alto valor agregado - e aos gaps apresentados na estrutura concorrencial deste setor no Brasil, reconhecidamente de alta concentração e com todas as implicações disto decorrentes, conforme anteriormente analisado.

$\mathrm{Na}$ esteira desta análise, a organização pesquisada consegue mapear vários desses aspectos, esboçando movimentações de defesa na tentativa de redução de sua vulnerabilidade em face dessa ameaça. Neste entendimento, são os fatores sistêmicos de competitividade - um grupo de forças exógenas, portanto - que possibilitam à oferta ilegal lograr seu espaço, uma vez que essa se beneficia das fragilidades do ambiente institucional e político, e aspectos geográficos e macroeconômicos. Valendo-se dessas fragilidades, ela supera as barreiras de entrada no setor e estabelece-se como ofertante ativo, ainda que competindo deslealmente.

Nessa perspectiva, o processo estratégico, aqui caracterizado como emergente, leva a organização a rever seus procedimentos e critérios para a tomada de decisão estratégica, motivada pela presença da concorrência desleal. Devido ao tempo relativamente curto em que essa força está atuando negativamente sobre a empresa (desde 1999) e à inexistência de tecnologias de gestão voltadas para a abordagem do fenômeno, a organização ainda não chegou a um nível de aprendizado que proporcione condições de enfrentar a concorrência desleal, com plena ciência de suas capacidades e vulnerabilidades. Isso faz com que haja em sua estrutura interna diferentes níveis de aprendizado e capacitação sobre a melhor forma de condução gerencial. A característica dessa ameaça leva ao enaltecimento das demandas por aprendizado, seja por processos internos, seja pela troca de experiências com outras organizações.

Sobressai a estratégia unificada de alinhar-se ao ambiente, caracterizada pelas ações junto à imprensa e à opinião pública, stakeholders e junto a organismos governamentais para aumento da fiscalização. Observa-se a grande importância desse quesito, porquanto, para organizações tabagistas, as dificuldades tendem a aumentar, quando se trata de obter a boa vontade de organismos externos, como 
órgãos governamentais e veículos de mídia. Essas dificuldades ainda estão vinculadas às suspeitas de envolvimento da organização com o contrabando até 1999, quando o mercado informal estava então ao seu favor.

A solução definitiva para o banimento da concorrência desleal reside na capacidade do poder público de agir contra ela. Não obstante, as ações tomadas dentro do escopo organizacional também têm influência sobre a condução dos fluxos de concorrência - legal e ilegal. Organizações, principalmente as de grande porte e participação de mercado, como é a do caso em estudo, interferem na estrutura concorrencial, incluindo o controle sobre os vetores necessários à constituição da oferta: fontes de suprimento, manufatura, distribuição e canalização de mão de obra especializada. Conclui-se que a ameaça da oferta ilegal faz com que a empresa necessite aprender as melhores formas de avaliar este impacto, gerir seus processos e rever os critérios para tomada de decisão.

\section{Artigo recebido em 09.11.2004. Aprovado em 11.05.2005.}

\section{Nota}

\footnotetext{
${ }^{1}$ Para o entendimento dos termos, adota-se neste estudo que 'desleal', 'ilegal' e 'informal' devem ser entendidos como termos sinônimos, quando referidos à forma como ocorrem esses processos de concorrência.
}

\section{ReferênCIAs Bibliográficas}

Bhagwati, J. N., \&

Hansen, B. (1974).

A theoretical analysis of smuggling. In J. N. Bhagwati (Ed.). Illegal transactions in international trade - theory and measurements (pp. 922). Amsterdam: North Holland Publishing Company.

Bhagwati, J. N.,

Krueger, A., \&

Wibulswasdi, C. (1974).

Capital flight from LDCs: a statistical analysis. In J. N. Bhagwati (Ed.). Illegal transactions in international trade - theory and measurements (pp. 148-154). Amsterdam: North Holland Publishing Company.

Bruyne, P.,

Herman J., \&

Schoretheete, M. (1991).

Dinâmica da pesquisa em ciências sociais. Rio de Janeiro: Francisco Alves.

Bueno, S. (2003, junho 16).

Valor agronegócios: cresce a fatia brasileira na exportação global de fumo. Valor Econômico, p. B12. 
Cabral, M. (2001).

Comércio ilegal de cigarros - aspectos nacionais e internacionais. Anais do Seminário Internacional Sobre Fraudes no Setor de Cigarros, Brasília, DF, Brasil, 1.

Diegues, C. (2003, março 26).

O Rei da Maracutaia. Revista Exame, pp. 62-64.

Deflem, M., \&

Henry-Turner, K. (2001).

Smuggling. In D. Luckenbill \& D. L. Peck (Eds.). The encyclopedia of criminology and deviant behavior (Vol. 2, pp. 473-475). Crime and Juvenile Delinquency. Philadelphia, PA: Brunner-Routledge.

Evelin, G. (1998, setembro 02).

Cigarro é prejudicial ao fisco. Revista Isto É. Recuperado em agosto 01, 2003, de http://www.zaz.com.br/istoe/ economia/150932.htm

Ferraz, J. C.,

Kupfer, D., \&

Haguenauer, L. (1996).

Made in Brazil. São Paulo: Campus.

Johnson, H. G. (1974).

Notes on the economic theory of smuggling. In J. N. Bhagwati (Ed.). Illegal transactions in international trade - theory and measurements (pp. 39-46). Amsterdam: North Holland Publishing Company.

Joossens L.,

Merriman D.,

Yurekli, A., \&

Chaloupka F. (2000).

Issues in the smuggling of tobacco products. In P. Jha \& F. J. Chaloupka (Eds.). Tobacco control in developing countries (pp. 393-405). Oxford: Oxford University Press.

Lagreca, R. H. (2003).

Análise de ações desenvolvidas na indústria de cigarros com a presença do mercado ilegal: o que uma empresa pode fazer para se defender dessa ameaça? Um estudo de caso da Souza Cruz S.A. Dissertação de Mestrado, Universidade do Vale do Rio dos Sinos. São Leopoldo, RS, Brasil.

Mariotto, F. L. (2003).

Mobilizando estratégias emergentes. Revista de Administração de Empresas, 43(2), 78-93.

Marshall, R. (2001).

Falsificação de cigarros e o crime organizado. Anais do Seminário Internacional Sobre Fraudes no Setor de Cigarros, Brasília, DF, Brasil, 1.

Merriman, D.,

Yurekli, A., \&

Chaloupka, F. J. (2000).

How big is the worldwide cigarettesmuggling problem? In P. Jha \& F. J. Chaloupka (Eds.), Tobacco control in developing countries. (pp. 365-392). Oxford: Oxford University Press.

Mintzberg, H. (2000).

Safári de estratégia: um roteiro pela selva do planejamento estratégico. Porto Alegre: Bookman.

Mintzberg, H., \&

Quinn, J. B. (2001).

O processo da estratégia (J. S. Cook, Trad.). (3a ed.). Porto Alegre: Bookman. (Obra original publicada em 1998). 
Naya, S., \&

Morgan, T. (1974).

The accuracy of international trade data: the case of Southeast Asian countries. In J. N. Bhagwati (Ed.). Illegal transactions in international trade-theory and measurements (pp. 123-137). Amsterdam: North Holland Publishing Company.

Nicolini, E. (1999, maio).

Panorama Setorial Gazeta Mercantil A Indústria do Fumo. Relatório da Gazeta Mercantil. Edição única. São Paulo.

Porter, M. (1986).

Estratégia competitiva: técnicas para análise de indústrias e da concorrência. Rio de Janeiro: Campus.

Porter, M. E. (1991).

Towards a dynamic theory of strategy. Strategic Management Journal. 12, 95-118.

Porter, M. E. (2002).

A nova era da estratégia. In C. A. Júlio \& J. S. Neto (Orgs.). Estratégia e Planejamento. São Paulo: Publifolha.

Soto, H. (2001).

O mistério do capital. Rio de Janeiro: Record.
Souza Cruz (2003).

Informações institucionais sobre a empresa Souza Cruz. Recuperado em junho, 2003, de http:// www.souzacruz.com.br/imprensa

Thursby, M.,

Jensen, R., \&

Thursby, J. (1991).

Smuggling, camouflaging, and Market Structure. The Quarterly Journal of Economics, 106(3), 789-814.

Thursby, J. G., \&

Thursby, M. C. (2000).

Interstate cigarette bootlegging: extent, revenue losses, and effects of federal intervention. National Tax Journal, 53(1), 59-77.

Verdi, M. F. (2001).

Repercussão do comércio ilegal de cigarros na economia nacional. Anais do Seminário Internacional Sobre Fraudes no Setor de Cigarros, Brasília, DF, Brasil, 1.

Yin, R. K. (2001).

Estudo de caso: planejamento e métodos (2a ed.). Porto Alegre: Bookman. 